Азиатско-Тихоокеанский регион: экономика, политика, право. 2021. Т. 24, № 4. С. 154-161. Pacific Rim: Economics, Politics, Law. 2021. V. 24, No 4. P. 154-161.

\title{
ПРАВО
}

Научная статья

УДК 347.963:342.7

https://doi.org/10.24866/1813-3274/2021-4/154-161

\section{ПРАКТИКА РАССМОТРЕНИЯ ИСКОВ, ПОДАННЫХ ОРГАНАМИ ПРОКУРАТУРЫ ХАБАРОВСКОГО КРАЯ В ЗАЩИТУ ПРАВ И СВОБОД ЧЕЛОВЕКА И ГРАЖДАНИНА}

\author{
Роман Валерьевич Хромин ${ }^{1}$, Дмитрий Владимирович Якунин ${ }^{2}$ \\ 1, 2 Дальневосточный филиал Российского государственного университета \\ правосудия, Россия, г. Хабаровск, ул. Восточное шоссе, 49 \\ 1 goral3333@mail.ru \\ 2 gpd-rgup@yandex.ru
}

Аннотащия. Во введении авторами описаны проблемы, возникающие в практике рассмотрения исков, поданных прокурором в защиту прав и свобод человека и гражданина в порядке статьи 46 Федерального закона от 17.01.1992 г. № 2202-1 «О прокуратуре Российской Федерации». В основной части статьи исследуются основные категории дел, рассматриваемых органами прокуратуры Российской Федерации в защиту прав и свобод граждан, а также анализируются законодательные пробелы, из-за которых судопроизводство по делам данной категории является недостаточно эффективным. Приводятся практические примеры исков, поданных органами прокуратуры Хабаровского края, а также судебных решений, вынесенных по результатам их рассмотрения. Завершая исследование, авторы на основе описанного материала приводят доказательства необходимости совершенствования законодательства, регулирующего судопроизводство по делам данной категории.

Ключевые слова: конституционные права, права и свободы человека и гражданина, процессуальная форма защиты, органы прокуратуры, трудовые права граждан, права инвалидов, гражданское судопроизводство, иск в защиту прав неопределённого круга лиц, критерии неопределённого круга лиц.

(C) Хромин Р. В., Якунин Д. В., 2021 
Для циттирования: Хромин Р. В., Якунин Д. В. Практика рассмотрения исков, поданных органами прокуратуры Хабаровского края в защиту прав и свобод человека и гражданина // Азиатско-Тихоокеанский регион: экономика, политика, право. 2021. T. 24, № 4. C. 154-161. https://doi.org/10.24866/1813-3274/2021-4/154-161

\title{
LAW
}

Original article

\section{PRACTICE OF CONSIDERING CLAIMS FILED BY THE PROSECUTOR OFFICE OF KHABAROVSKY REGION FOR THE PROTECTION OF HUMAN RIGHTS AND FREEDOMS}

\author{
Roman V. Khromin ${ }^{1}$, Dmitriy. V. Yakunin ${ }^{2}$ \\ Far Eastern Branch of the Russian State University of Justice, Khabarovsk, Russia; \\ Khabarovsk, 49 Vostochnoye Shosse St. \\ 1 goral3333@mail.ru \\ 2 gpd-rgup@yandex.ru
}

Abstract. In the introduction, the authors describe the problems that arise in the practice of considering claims filed by the prosecutor for the protection of human and civil rights and freedoms in accordance with Article 46 of the Federal Law of January 17, 1992, No. 2202-1 "On the Prosecutor's Office of the Russian Federation". The main part of the article examines the main categories of cases considered by the prosecutor's office of the Russian Federation in defense of the rights and freedoms of citizens, and also analyzes the legislative gaps that make legal proceedings in cases of this category insufficiently effective. Practical examples of claims filed by the prosecutor's office of the Khabarovsk Territory, as well as court decisions made as a result of their consideration are given. Concluding the article, the authors rely on the described material to provide the evidence of the need to improve the legislation governing legal proceedings in cases of this category.

Keywords: constitutional rights, human and civil rights and freedoms, procedural form of protection, prosecution bodies, labor rights of citizens, rights of persons with disabilities, civil proceedings, a claim in defense of the rights of an indefinite circle of persons, criteria of an indefinite circle of persons.

For citing: Khromin R. V., Yakunin D. V. Practice of considering claims filed by the prosecutor office of Khabarovsky region for the protection of human rights and freedoms // Pacific RIM: Economics, Politics, Law. 2021. V. 24, No 4. P. 154-161. https://doi.org/10.24866/1813-3274/2021-4/154-161. 


\section{Введение}

Важнейшим элементом комплекса прав и свобод человека и гражданина является право защищать их в суде. Анализ положений статьи 46 Конституции РФ позволяет констатировать, что каждому человеку в нашей стране гарантировано право на судебную защиту. Правом подачи иска о защите прав и свобод человека и гражданина наделён прокурор. Согласно закону, любой гражданин Российской Федерации вправе обратиться в суд с заявлением в защиту прав, свобод и законных интересов граждан или неопределённого круга лиц. Полномочия прокурора в данной сфере регламентированы Федеральным законом от 17.01.1992 года № 2202-1 «О прокуратуре Российской Федерации». Однако сам процесс рассмотрения исков, поданных прокурором в защиту прав и свобод человека и гражданина в порядке статьи 46 указанного закона, осложнён рядом обстоятельств, порождаемых несовершенством гражданско-процессуального законодательства Российской Федерации, слабой проработкой понятийного аппарата, а также ошибками, допускаемыми на этапе составления исковых заявлений.

\section{Основная часть исследования}

Согласно ст. 27 Федерального закона от 17.01.1992 г. № 2202-1 «О прокуратуре Российской Федерации», прокурор рассматривает заявления, жалобы и иные сообщения о нарушении прав и свобод человека и гражданина, а в случае выявления факта их нарушения предъявляет иск и поддерживает его в гражданском и арбитражном процессе.

Так, ежегодно органами прокуратуры Хабаровского края выявляется не менее 20 тыс. нарушений прав и свобод человека и гражданина, причём в последние годы данный показатель имеет тенденцию к увеличению [1]. В отдельную категорию следует выделить иски о защите трудовых прав граждан. Согласно полученным данным, в период 2018-2019 гг. прокуратурой Охотского района Хабаровского края подготовлено и направленно в суд 134 иска в защиту трудовых прав граждан на общую сумму 6451 тыс. руб. [2]. Примером может служить иск о взыскании задолженности по заработной плате с ИП Н. М. Сиверцевой в пользу Т. Е. Перевозной. Решением Охотского районного суда от 28.04.2018 г. требования прокурора удовлетворены в полном объёме. С индивидуального предпринимателя Н. М. Сиверцевой взысканы заработная плата и расчёт по увольнению в пользу Т. Е. Перевозной в размере 189113 руб. [4].

Решение об удовлетворении исковых требований прокурора о взыскании задолженности по заработной плате принял 28 ноября 2019 г. Индустриальный районный суд г. Хабаровска. По решению суда с ООО «Компания строительные технологии» в пользу Мукомеловой Евгении Павловны была взыскана задолженность по заработной плате в сумме 51723 руб. 66 коп., компенсация за её задержку в сумме 853 руб. 00 коп., всего 52576 руб. 66 коп. [6]. 
Хромин Р. В., Якунин Д. В. Практика рассмотрения исков, поданных органами прокуратуры Хабаровского края в защиту прав и свобод человека и гражданина

В других случаях суды отказывают в удовлетворении иска о защите трудовых прав в связи с пропуском органами прокуратуры срока обращения в суд. В качестве примера можно привести гражданское дело по искам прокурора Охотского района Хабаровского края в интересах К. Г. Панфилова, А. С. Орлова, О. А. Яйчун к рыболовецкой артели «Иня» о взыскании задолженности по заработной плате, денежной компенсации за несвоевременную выплату заработной платы [3].

Органы прокуратуры, зная, что в трёхмесячный срок ими должны быть приняты меры к обращению в суд в интересах заявителя, тем не менее пропустили его, хотя никаких препятствий к такому обращению ни истцами, ни прокурором в суд предоставлено не было. Тем самым было нарушено право заявителей на защиту трудовых прав, гарантированных Конституцией РФ и трудовым законодательством РФ.

Анализ практики рассмотрения исков, поданных прокурорами Хабаровского края в защиту прав и свобод человека и гражданина, показал, что не менее 5\% coставляют иски в защиту прав инвалидов на беспрепятственный доступ к объектам социальной и транспортной инфраструктуры [1].

Так, транспортный прокурор г. Комсомольска-на-Амуре Хабаровского края в обоснование заявленных требований указал, что Дальневосточная дирекция пассажирских обустройств (филиал ОАО «РЖД») нарушает Федеральный закон № 52-Ф3 от 30.03.1999 «О санитарно-эпидемиологическом благополучии населения», а также Приказ Минтранса России от 06.11.2015 № 329 «Об утверждении Порядка обеспечения условий доступности для пассажиров из числа инвалидов пассажирских вагонов, вокзалов, поездов дальнего следования и предоставляемых услуг на вокзалах и в поездах дальнего следования». Решением Центрального районного суда г. Хабаровска от 28 января 2020 г. по делу № 2-205/2020 исковые требования транспортного прокурора удовлетворены в полном объёме [7].

В отдельную группу можно выделить иски, поданные органами прокуратуры в защиту права инвалидов по зрению на беспрепятственный доступ к информационным ресурсам. Примером может служить иск прокурора Охотского района Хабаровского края к МКОУ СОШ имени С. С. Вострецова (Хабаровский край, Охотский район, с. Вострецово, пер. Школьный, д. 2) о возложении обязанности по соблюдению требований закона при использовании сайта в сети Интернет 1789956.mya5.ru. Основанием для подачи иска явилось нарушение положений Федерального закона «О социальной защите инвалидов в Российской Федерации». Решением Охотского районного суда Хабаровского края от 28 апреля 2017 г. по делу № 2-110/2017 исковые требования прокурора удовлетворены в полном объёме [5].

Отдельное внимание следует уделить практике защиты прав детей-сирот и детей, оставшихся без попечения родителей. Проведённый анализ показал, что в 2018-2019 гг. прокурорами Охотского района Хабаровского края в суды общей юрисдикции было направлено 117 заявлений в защиту прав несовершеннолетних, в 
том числе детей-сирот и детей, оставшихся без родительского попечения [2]. Так, по результатам прокурорской проверки в КГКУ «Организация, осуществляющая обучение, для детей-сирот, оставшихся без попечения родителей "Детский дом № 36" г. Охотска» установлено, что в данном учреждении не соблюдаются санитарноэпидемиологические требования, предъявляемые к хранению продуктов, а также к наличию источников резервного горячего водоснабжения для обеспечения нужд несовершеннолетних. По постановлению прокурора должностное лицо КГКУ «Организация, осуществляющая обучение, для детей-сирот, оставшихся без попечения родителей "Детский дом № 36" г. Охотска» оштрафовано на 3000 руб. [1].

Согласно статистическим данным, ежегодно органами прокуратуры Хабаровского края выявляется более 9 тыс. правонарушений в жилищной сфере. В связи с этим значительное число исков (не менее $30 \%$ ), подается в защиту жилищных прав граждан [1]. Так, на основании поручения прокуратуры Хабаровского края от 12.07.2019 г. № 34/07-2019 проведена проверка соблюдения жилищного законодательства в отношении Д. Е. Адюн, в ходе которой выявлены нарушения закона. Из материалов дела следует, что жилое помещение за Д. Е. Адюн при присвоении статуса сироты не закреплялось, поскольку родители ребенка на момент смерти проживали в ветхом жилье. Учётное дело Д. Е. Адюн в Министерство ЖКХ Хабаровского края направлено не было по неизвестным причинам. Решением Центрального районного суда г. Хабаровска от 18 сентября 2019 г. по делу № 2-6829/2019 [8] исковые требования прокурора г. Николаевска-на-Амуре в интересах Д. Е. Адюн удовлетворены в полном объёме.

Согласно гражданскому процессуальному законодательству, прокурор вправе обратиться в суд с исковым заявлением в защиту прав и свобод неопределенного круга лиц. Примером может служить иск прокурора к Администрации г. Хабаровска в защиту прав, свобод и законных интересов неопределённого круга лиц, о понуждении к совершению действий, связанных со сносом и санитарной обрезкой деревьев, в соответствии с заключением управления по охране окружающей среды. Решением Центрального районного суда г. Хабаровска от 9 сентября 2016 г. исковые требования удовлетворены [9].

Иск прокурора в интересах неопределённого круга лиц наилучшим образом согласуется с целями обеспечения конституционных прав и свобод граждан. Однако законодатель, наделяя прокурора правом подачи иска в защиту прав неопределённого круга лиц, не привёл в ГПК РФ значение этого понятия. В результате такого правового пробела суды толкуют понятие «неопределенный круг лиц» поразному, а иногда необоснованно отказывают в удовлетворении иска прокурора. Наиболее часто данные решения выносятся по искам, касающимся нарушений трудовых прав граждан. Так, в 2018 г. прокурор г. Комсомольска-на-Амуре Хабаровского края, действуя в интересах неопределённого круга лиц КГБУЗ «Городская больница № 2», подал иск к Министерству здравоохранения Хабаровского края, 
Хромин Р. В., Якунин Д. В. Практика рассмотрения исков, поданных органами прокуратуры Хабаровского края в защиту прав и свобод человека и гражданина

Комитету по управлению имуществом г. Комсомольска-на-Амуре о возложении обязанностей по проведению ремонтных работ для обеспечения надлежащих условий труда работников КГБУЗ «Городская больница № 2». Однако судом в принятии искового заявления было отказано. В обоснование отказа суд указал, что по факту прокурор действовал не в интересах неопределённого круга лиц, а в целях защиты прав и свобод вполне определённого круга работников медицинского учреждения, каждый из которых может быть индивидуализирован. Проанализировав нормы закона, суд пришел к выводу, что чётких критериев определения неопределённого круга лиц в гражданском судопроизводстве не закреплено. В то же время суд указал, что сообразно смыслу статьи 45 ГПК РФ группу лиц следует считать неопределённой, если невозможно установление личности каждого из участников. С учётом данных обстоятельств в принятии иска было отказано. В другом случае Железнодорожный районный суд г. Хабаровска неверно истолковал понятие «неопределённый круг лиц». Вследствие этого судья отказался принимать иск прокурора, который был составлен в интересах неопределённого круга лиц Муниципального автономного общеобразовательного учреждения г. Хабаровска «Средняя школа № 26» [1].

Проведённый анализ показал, что наиболее частой ошибкой органов прокуратуры является недостаточность информации о нарушенных правах и свободах, а также ссылок на законы либо иные нормативно-правовые акты, закрепляющие способы их защиты. Примером может служить иск прокурора Солнечного района Хабаровского края, поданный в защиту интересов неопределённого круга лиц к КГКУ «Хабаровскуправтодор» о понуждении к совершению действий по выполнению мероприятий по ремонту на участке автомобильной дороги г. Комсомольск-наАмуре - п. Берёзовый - п. Могды - п. Чегдомын с 6 по 32 км. В нарушение требований ч. 3 ст.131 ГПК РФ в иске не было указано, в чём выражается действительная реальная угроза нарушения прав неопределённого круга лиц. Решением Кировского районного суда Хабаровского края от 18 сентября 2019 г. по делу № 2-1253/2019 исковые требования прокурора удовлетворены частично [10].

\section{Выводы}

Анализ практических аспектов деятельности прокуратуры Хабаровского края позволил авторам выявить факты нарушения прокурорами сроков подачи исков в защиту трудовых прав граждан, а также ошибки, допускаемые на этапе составления исковых заявлений. В ряде случаев это создаёт предпосылки для отказа в удовлетворении исковых требований, при этом нарушаются права и свободы граждан. Не способствует эффективной защите прав и свобод и отсутствие в гражданском процессуальном законодательстве легальной дефиниции «неопределённый круг лиц», что ведёт к различному его толкованию судами, является причиной необоснован- 
ных отказов в принятии иска. Считаем, что разъяснение данного понятия в отдельном Постановлении Верховного суда РФ будет способствовать выработке единой правоприменительной практики, повысит эффективность защиты прав и свобод человека и гражданина в Российской Федерации.

\section{Список источников}

1. Доклад о деятельности органов прокуратуры Хабаровского края за 20162019 гг. - URL: http://www.prokurorhbr.ru/content/statistics (дата обращения: 25.09.2021).

2. Отчёт о деятельности прокуратуры Охотского района Хабаровского края за 2018-2019 гг. // Архив прокуратуры Охотского района Хабаровского края. - Неопубл.

3. Решение Охотского районного суда Хабаровского края от 12.02.2016 г. по гражданскому делу № 2-38/2016. - URL: http://sudact.ru (дата обращения: 25.09.2021).

4. Решение Охотского районного суда от 28.04.2018 г. по гражданскому делу № 4-87/2018 - URL: http://sudact.ru (дата обращения: 25.09.2021).

5. Решение Охотского районного суда Хабаровского края от 28 апреля 2017 г. по делу № 2-110/2017. - URL: http://sudact.ru (дата обращения: 25.09.2021).

6. Решение Индустриального районного суда г. Хабаровска от 28 ноября 2019 г. по гражданскому делу № 2-4423/2019. - URL: http://sudact.ru (дата обращения: 19.09.2021).

7. Решение Центрального районного суда г. Хабаровска от 28 января 2020 г. по гражданскому делу № 2-205/2020. - URL: http://sudact.ru (дата обращения: 20.09.2021).

8. Решение Центрального районного суда г. Хабаровска от 18 сентября 2019 г. по делу № 2-6829/2019. - URL: http:/sudact.ru (дата обращения: 23.09.2021).

9. Решение Центрального районного суда г. Хабаровска от 9 сентября 2016 г. по делу № 2-6432/2016. - URL: http://sudact.ru. (дата обращения: 23.09.2021).

10. Решение Кировского районного суда Хабаровского края от 18 сентября 2019 г. по делу № 2-1253/2019. - URL: http://sudact.ru (дата обращения: 25.09.2021).

\section{Информация об авторах}

Р. В. Хромин - магистрант кафедры государственно-правовых дисциплин Дальневосточного филиала Российского государственного университета правосудия.

Д. В. Якунин - кандидат юридических наук, доцент кафедры государственноправовых дисциплин Дальневосточного филиала Российского государственного университета правосудия. 


\section{References}

1. Report on the activities of the prosecutor's office of the Khabarovsk Territory for 2016-2019). Available at: http://www.prokurorhbr.ru/content/statistics (accessed 25 September 2021). (In Russian)

2. Report on the activities of the Prosecutor's Office of the Okhotsk District of the Khabarovsk Territory for 2018-2019. Archive of the Prosecutor's Office of the Okhotsk District of the Khabarovsk Territory. (Unpublished). (In Russian).

3. The decision of the Okhotsk District Court of the Khabarovsk Territory of 12.02.2016 in the civil case No. 2-38/2016. Available at: http://sudact.ru (accessed 25 September 2021). (In Russian).

4. The decision of the Okhotsk District Court of 28.04.2018 in the civil case No. 4-87/2018. Available at: http://sudact.ru (accessed 25 September 2021). (In Russian).

5. Decision of the Okhotsk District Court of the Khabarovsk Territory dated April 28, 2017 in case No. 2-110/2017. Available at: http://sudact.ru (accessed 25 September 2021). (In Russian).

6. Decision of the Industrial District Court of Khabarovsk dated November 28, 2019 in civil case No. 2-4423/2019. Available at: http://sudact.ru (accessed 19 September 2021). (In Russian).

7. The decision of the Central District Court of Khabarovsk dated January 28, 2020 in civil case No. 2-205/2020. Available at: http://sudact.ru (accessed 20 September 2021). (In Russian).

8. Decision of the Central District Court of Khabarovsk dated September 18, 2019 in case No. 2-6829/2019. Available at: http://sudact.ru (accessed 23 September 2021). (In Russian).

9. Decision of the Central District Court of Khabarovsk dated September 9, 2016 in case No. 2-6432/2016. Available at: http://sudact.ru (accessed 23 September 2021). (In Russian).

10. Decision of the Kirovsky District Court of the Khabarovsk Territory dated September 18, 2019 in case No. 2-1253/2019. Available at: http://sudact.ru (accessed 25 September 2021). (In Russian).

\section{Information about the authors}

R. V. Khromin - Master student of the Department of State and Legal Disciplines of the Far Eastern Branch of the Russian State University of Justice.

D. V. Yakunin - Candidate of Law, Associate Professor of the Department of State and Legal Disciplines of the Far Eastern Branch of the Russian State University of Justice. 